\title{
ANALYSIS AND PREDICTION OF GREENHOUSE GAS EMISSION USING FEEDFORWARD NEURAL NETWORK
}

\author{
Pranali K. Kosamkar ${ }^{1}$, Dr. Vrushali Y. Kulkarni ${ }^{2}$ \\ ${ }^{1}$ MIT-World Peace University, Pune, 444038, India \\ ${ }^{2}$ MIT-World Peace University, Pune, 444038, India \\ I pranali.kosamkar@mitwpu.edu.in \\ ${ }^{2}$ vrushali.kulkarni@mitwpu.edu.in
}

\begin{abstract}
Greenhouse Gas (GHG) emission is caused by decomposition of biomass and dead plant residues, livestock enteric fermentation in ruminants, and burning of crop residues. As the concentration of GHG rises it raises the temperature on the globe causing the Global Warming. Alterations in agriculture management practices may reduce the GHG emission. Therefore, there is a need to analyze and forecast the GHG emission from Agriculture. We have built the Feedforward Neural Network using sequential neural network in keras for predicting $\mathrm{CO}_{2}$ and $\mathrm{CH}_{4}$ emission for Onion crop from open farm and poly house. We selected Onion for our study because Onion is one of the second most important commercial crops of the India. The GHG emission may vary in open farm and poly house for onion crop because the environment is controlled in poly house as compared to open farm. For this study we collected the field data of soil attributes, climatic attributes and $\mathrm{CO}_{2}$, $\mathrm{CH}_{4}$ greenhouse gases from the experiment field. We hyper tune the model with 3, 4 and 5 layers with different epoch. We have used Root mean squared error (RMSE), Mean squared error (MSE) and R-square as a coefficient of correlation for model prediction accuracy. Model predicted that Nitrogen, Moisture, Pressure, Humidity and Temperature are major affecting factors for emission of GHG for onion crop from open farm and poly house. The model indicates good prediction response for GHG emission with major influencing attribute for onion crop.
\end{abstract}

Keywords: Agriculture, Deep Learning, Feedforward Neural Network, Greenhouse Gas Emission, Soil.

\section{Introduction}

"Absorbing heat energy emitted from earth's surface and reradiating it back to earth's surface, thus contributing to the greenhouse effect which leads to Global Warming" is the property of greenhouse gas. According to World Meteorological Organization (WMO) Greenhouse Gas Bulletin the "global average concentrations of carbon dioxide $\left(\mathrm{CO}_{2}\right)$ reached 407.8 parts per million (ppm) in 2018 up from 405.5 parts per million in 2017". Fig. 1 shows how $\mathrm{CO}_{2}$ concentration is increasing from1990 to 2018. According to Safwan Mohammed et al. [18] Agriculture is responsible for $13.5 \%$ emission of GHG and thus to variation in climate. Climate variation have an impact on agriculture in various way like rainfall pattern change, more floods, change in average temperature and sea level rise. Climate variation is directly affecting the food production across the globe. As per the United Nations Department of Economic and Social Affairs (UN/DESA) the global population increases to 9.7 billion people by 2050 . The growth of population and demand for food require producing an adequate amount of food. So, different practices such as use of fertilizer, crop residue, soil management, land management etc. used by the farmers. These practices have their adverse effect on the environment to meet the needs like food demand, crop yield etc. these process frequently enhance the emission of GHG. One of the solutions to climate variation is to reduce the emission of greenhouse gases. Therefore, there is a need of 
analysis and prediction of greenhouse gas emission from agriculture sector.

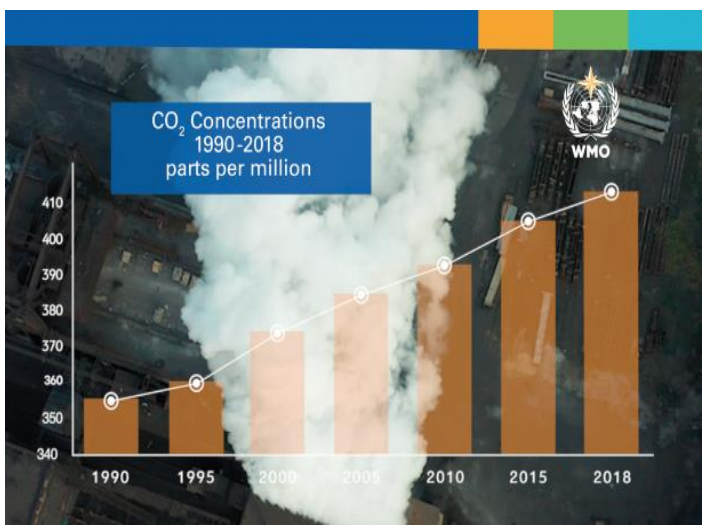

Figure 1.CO2 concentrations from 1990-2019 parts per million [Source: 21]

The motive of the study is to design the Feedforward Neural Network (Deep Learning Model) for analysis and prediction of GHG i.e. $\mathrm{CO}_{2}$ and $\mathrm{CH}_{4}$ emission for Onion crop from Open farm and Poly house. We collected the field data of soil, climatic attribute and $\mathrm{CO}_{2}, \mathrm{CH}_{4}$ gases values from the farm. We also predicted the major influencing attributes for $\mathrm{CO}_{2}$ and $\mathrm{CH}_{4}$ emission for Onion crop from Open farm and Poly house. We selected Onion for our study because Onion is one of the second most important commercial crops of the India which is next to Potato. Also Onion can be grown up in a climatic situation such as temperate, tropical and subtropical climate. The GHG emission may vary in open farm and poly house for onion crop because the environment is controlled in poly house as compared to open farm. The paper is structured as follows: the Section I introduces the idea about emission of greenhouse gas from agriculture. Section II present survey of various work done, section III describe the methodology for analysis and prediction of greenhouse gas emission from agriculture. Section IV presents analysis of results obtained and section $\mathrm{V}$ provides the conclusion.

\section{Literature Survey}

Different studies are conducted to analyze and forecast the GHG emission from agriculture soil and climatic attribute for different crops. The survey shows some of the work done in this area. According to Kingsley Appiah et al. implemented fully connected two-layer feed-forward neural.
They have used Levenberg-Marquardt algorithm for forecasting the emission of selected emerging economies using data from 1971 to 2013 from World Development Indicators and FAOSTAT database. Their result showed that the model errors are less than 0.05 and their model forecast potential carbon dioxide emission in emerging economic with greatest accuracy [15]. Forkuor $G$ et al. implemented four statistical predicting models, for mapping soil samples to spatial distribution of six soil properties. Their result shows that algorithm work better than multiple linear regression for forecasting of soil properties [10]. Leopord Uwamahoro \& Dr. Papias Niyigena used Long Short Term Memory recurrent neural network model for forecasting the greenhouse emission from agriculture activities in Rwanda. Their result showed high accuracy in prediction of $97.64 \%$ and $2.36 \%$ in the loss [16]. Alicja Kolasa-Wieccek used ANN for forecasting direct $\mathrm{N}_{2} \mathrm{O}$ emissions from Agricultural Soils. Their sensitivity analysis with multilayer perceptrons (MLP) 9-4-1 confirms that use of nitrogen fertilizer has the major role for $\mathrm{N}_{2} \mathrm{O}$ emission. Also for formation of $\mathrm{N}_{2} \mathrm{O}$ emission participate cattle and pigs are mainly important with MLP16-5-1 [1]. Chusnul Arif et al. have used ANN model for estimating GHG emission from paddy irrigation with different water management. Their result shows that the coefficients of determination (R2) values were 0.84 and 0.76 for $\mathrm{CH}_{4}$ and $\mathrm{N}_{2} \mathrm{O}$ prediction respectively with high precision [8]. Ashkan Nabavi-Pelesaraei et al. have used ANN for forecasting energy use and GHG emission of watermelon production system for three different farm sizes. Their result shows that ANN model with 11-10-2 structure works better with coefficient of determination (R2) as 0.969 and 0.995 for yield and GHG emission respectively [2]. B. Khoshnevisan et al. have used ANN for predicting GHG emission of Strawberry production. Their result shows that chemical fertilizer was the major significant feature for $\mathrm{GHG}$ emission. The ANN model with 11-6-10-2 structure works best with lower RMSE and MAE values for forecasting the output energy and GHG emission [6]. Homa Hosseinzadeh-Bandbafha et al. concluded that adaptive neuro-fuzzy inference system predicts energy output and greenhouse gas emissions more accurately than the ANN [12]. Similarly Guifang Liu et al. investigated total greenhouse gas emission for wheat production. 
Their result showed that $\mathrm{N}_{2} \mathrm{O}, \mathrm{N}$ fertilizer, compound fertilizer, electricity, and diesel oil were the main GHG emission sources [11]. Cai-Ma designed "a carbon emission prediction model of agroforestry ecosystem based on support vector regression. Seven carbon sources, including root decomposition, chemical fertilizer, pesticide, agricultural film, agricultural irrigation, agricultural machinery and farmland tillage, were selected as influencing factors of carbon emissions in agroforestry ecosystem. The experimental result shows that the model can predict carbon emissions of agroforestry ecosystem quickly and completely" [7]. Hyeon Ji Song et al. have suggested that Autumn straw application significantly decreased $\mathrm{CH}_{4}$ intensity by average $24-65 \%$ over the spring straw application [13]. Safieh Javadinejad et al. have analyzed the monthly and seasonal methane gas. They conclude that rise in $\mathrm{CH}_{4}$ concentration is majorly related to low vegetation cover and high temperature [19]. Johnson Masaka et al. have suggested that "improved agronomic practices for increased crop productivity can be used as a mitigation factor for reducing the contribution of agriculture in the global emissions of $\mathrm{N}_{2} \mathrm{O}$ " [14]. Aung Zaw Oo et al. have assessed $\mathrm{CH}_{4}$ emission in lowland rice farms. Their result shows $\mathrm{CH}_{4}$ emissions at non-fertilized parts were more than those at fertilized part [4]. Andreas Kamilaris et al. did analysis how deep learning techniques applied to agriculture sector. Their analysis shows that deep learning provide good prediction accuracy as compared to existing image processing methods used in agriculture sector [3]. Dinesh Panday et al. have shown that there is relationship between greenhouse gases and soil pore space indices and soil water for corn/soybean [9]. B. J. Zebarth, et al. have analyzed and recommended that improved managing of fertilizer $\mathrm{N}$ can reduce nitrate intensity in corn farm [5]. Witsanu Attavanich analyzed and concluded that temperature and precipitation considerably establish the farmland values and greenhouse warming [20]. Mphethe Tongwanea et al. have compared different crop production and management practices for GHG emission. They suggested that, "mitigation plans of emissions from field crops in South Africa need to focus more on sustainable improvement of soil fertility, optimum application of synthetic $\mathrm{N}$ fertilizer and crop residues" [17]. Kerstin Jantke et al. did the survey of German farmers regarding reducing the greenhouse gas emission and complying with the governance program. They analyze that German farmers are familiar of variation in climate change and feel a responsibility of reducing greenhouse gas emissions [23]. H. Flessa et al. have analyzed aggregate greenhouse gas emission from two different farming patterns. Their result shows that moving to organic farming from conventional farming led to reduction in emission per hectare, but yield-related emission were not reduced [24]. Sylvia H. Vettera et al. have studied the association of Greenhouse gas emission with major food commodities production in India using Cool Farm Tool [25]. According to Grant, B et al. have used The Denitrification-Decompostion (DNDC) model to figure out the influence of change in management practices on $\mathrm{N}_{2} \mathrm{O}$ emission. Their result shows that moving from cultivated land to grassland, conventional tillage to no-tillage and the reduction of summer allow in crop rotations increases $\mathrm{C}$ sequestration and decrease net GHG emissions [26]. Abderrachid Hamrani et al. have used machine learning algorithm namely classical regression, shallow learning and deep Learning LSTM for forecasting soil greenhouse gas emission. Their result shows that LSTM model give the good performance in prediction of $\mathrm{N}_{2} \mathrm{O}$ and $\mathrm{CO}_{2}$ fluxes [27]. After studying the research papers we found that most of the researchers either use soil or climatic variable for emission of GHG for crops like corn, rice, strawberry etc. but they have not compare the emission of GHG for same crop under the poly house and open farm cultivation. This study will help the farmers for better understanding of agriculture management practices.

\section{Methodology and Material}

A variety of machine learning models have been used for analysis and prediction of GHG emission in agriculture. We have built the deep learning model for analysis and prediction of GHG emission for onion crop from open farm and poly house. For this study is collected field data of soil and climatic attributes from Directorate of Onion \& Garlic Research, Rajgurunagar, Pune (Maharashtra). We collected soil and climatic data from the farm during January 2020 to March 2020 weekly twice for experimental purpose. The soil attributes considered are N-P-K values (Nitrogen, Phosphorous and Potassium), $\mathrm{pH}$ values, Soil Type, 
Soil Temperature and Moisture. The Climatic attributes considered are Pressure, Temperature, Humidity, and Wind Speed. The GHG emission data considered are $\mathrm{CO}_{2}$ and $\mathrm{CH}_{4}$. The focus of this study is to analyze and predict the $\mathrm{CO}_{2}$ and $\mathrm{CH}_{4}$ emission for Onion crop from Open farm and Poly house. The study also finds the major influencing attribute for Onion crop from Open farm and Poly house. Fig. 2 shows the working of model.

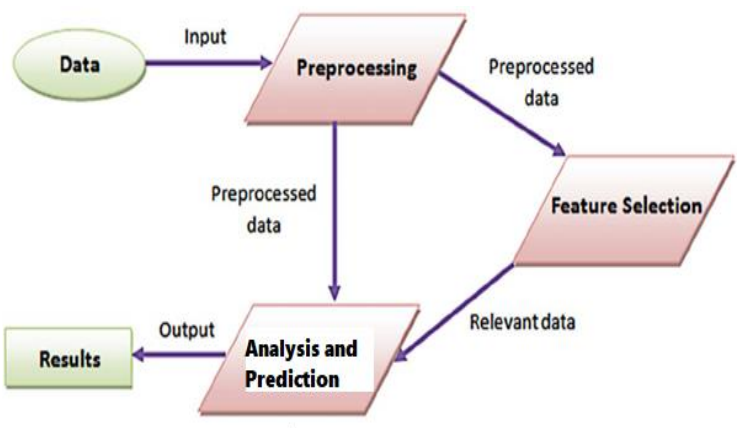

Figure 2. System Architecture

With the use of different sensors the attributes related to soil, climatic and GHG emissions are collected with Arduino UNO Microcontroller. The DHT11 sensor is a commonly used temperature and humidity sensor. Agrinex Solution SOIL DOCTOR PLUS (HC $106 \mathrm{NPKpH}$ ) is integrated kit is used to access primary nutrients (N-P-K) as well as $\mathrm{pH}$ levels of soil. For measuring the soil $\mathrm{pH}$ and moisture we used 2 in 1 Soil PH and moisture sensor. MQ-4 is a methane gas sensor that detects the concentration of methane gas in the air. The MQ-135 Gas sensors are used for measuring of $\mathrm{CO}_{2}$ gas. Whereas the Google weather app is used for collection of climatic attributes. The data measured is directly saved on the cloud (Thingspeak) from where it can be downloaded. The preprocessing of the data is done like converting the text data into numerical. The text values of field Nitrogen, Phosphorus, and Potassium (NPK) is converted into 0, 1, 2 from high, low and medium. Further preprocessing is done using normalization. This dataset is normalized using minmax scalar function i.e. with normalization we change the soil, climatic and GHG emission data to common range. We further perform the feature selection to reduce the training time, over fitting and to improve the accuracy of the model. In the feature selection we select the features which are important to predict the response variable.

\subsection{Feedforward Neural Network}

Power of the model prediction is depends on the right adjusted weight and bias. The training phase performs feedforward i.e. calculate the predicted output and backpropagation which update the weights and bias. Each iteration of training phase performs these task i.e. feedforward and backpropagation. Neural Network mathematically it is written as follows,

$$
\hat{\mathrm{Y}}=\quad \sum_{i=1}^{n} \text { Wixi }+\quad \mathrm{b}
$$

Where,

$\hat{\mathrm{Y}}$ is output variable,

$\mathrm{W}$ is weight applied to layer

$\mathrm{x}$ input variables

$\mathrm{b}$ is bias

$\mathrm{n}$ is the number of observation used in experiment

We have used keras framework to create a feedforward neural network stacking layer by layer using Sequential model. The model consists of 4 layers including the input and output layer. The input layer or the first layer has 50 neurons and we are considering 11 input parameters with activation function ReLu. The second layer or the first hidden layer has 25 neurons with activation function ReLu. The third layer has 12 neurons using ReLu as the activation function. A dropout layer is added to optimize the model. The output layer uses sigmoid as the activation function to generate the final output. Through evaluation of analysis of results, the model was hyper tuned by optimizing the number of neurons, batch size and number of epochs. Using R-squared error function, Epoch $=1000$ was found to be optimal and was selected for the particular model minimizing RMSE and using MSE and R-Squared as metrics.

\section{Result and Discussion}

We tried to predict and analyze GHG emission values from soil and climatic attributes for Onion crop from Open field and Poly house. We used RMSE, MSE and R-Squared values for model performance. 


\subsection{Prediction of $\mathrm{CO}_{2}$ emission from Open farm}

We use inbuilt function to find the weight for the important feature for prediction of $\mathrm{CO}_{2}$ emission from open farm. For open farm environment humidity with weight $0.0020 \pm 0.0002$ followed by wind speed with weight $0.0005 \pm$ 0.0001 are most important features for emission of $\mathrm{CO}_{2}$. Fig. 3 shows the weight values along with features.

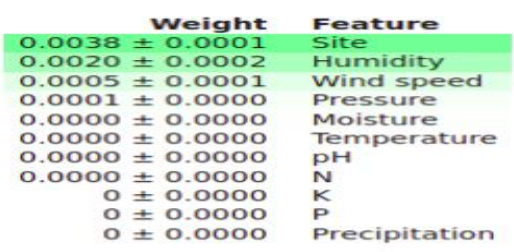

Figure 3. Weight feature of soil and climatic attribute

We hyper tune the model with different layer i.e. 3 layer, 4 layer and 5 layer with different epoch values to get the best value for RMSE. The experimental result shows that model with 4 layer gives good accuracy in terms of RMSE values i.e. 0.0112 as compared to 3 layer and 5 layer model with 1000 epoch. Table 1 show the RMSE values with number of layer and epoch values and fig. 4 graph shows comparison of the number of epoch and error values. Lower the error good is the prediction model.

Table 1. Number of epoch and layer wise RMSE values

\begin{tabular}{|l|l|c|l|}
\hline Epoch & 3 Layer & 4 Layer & 5 Layer \\
\hline 50 & 0.0344 & 0.0313 & 0.0376 \\
\hline 100 & 0.0280 & 0.0277 & 0.0466 \\
\hline 150 & 0.0315 & 0.0274 & 0.0576 \\
\hline 500 & 0.0173 & 0.0172 & 0.0135 \\
\hline 700 & 0.0144 & 0.0133 & 0.0141 \\
\hline 1000 & 0.0125 & 0.0112 & 0.0129 \\
\hline
\end{tabular}

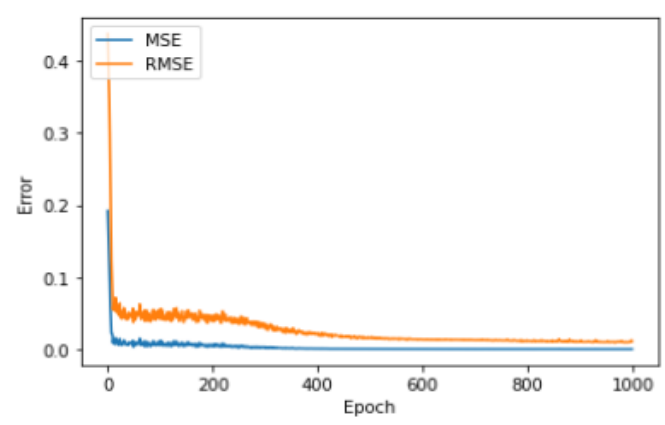

Figure 4. Feedforward Neural NetworkComparing errors with no of epoch

\subsection{Prediction of $\mathrm{CO}_{2}$ emission from Poly house}

For poly house environment humidity with weight $0.0003 \pm 0.0002$ is most important feature as compared to other features for emission of $\mathrm{CO}_{2}$. Fig. 5 shows the weight values along with features.

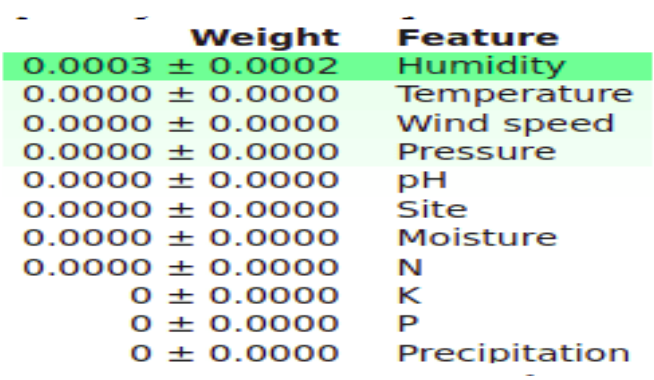

Figure 5. Weight feature of soil and climatic attribute

The experimental result shows that model with 4 layer gives good accuracy in terms of RMSE values i.e. 0.0238 with 1000 epoch. Table 2 shows the RMSE values with number of layer and epoch values and fig. 6 graph shows comparison of the number of epoch and error values.

Table 2. Number of epoch and layer wise RMSE values

\begin{tabular}{|l|l|c|l|}
\hline Epoch & 3 Layer & 4 Layer & 5 Layer \\
\hline 50 & 0.0367 & 0.0504 & 0.0482 \\
\hline 100 & 0.0281 & 0.0570 & 0.0515 \\
\hline 150 & 0.0244 & 0.0462 & 0.0481 \\
\hline 500 & 0.0255 & 0.0298 & 0.0398 \\
\hline 700 & 0.0206 & 0.0292 & 0.0411 \\
\hline 1000 & 0.0246 & 0.0238 & 0.0243 \\
\hline
\end{tabular}

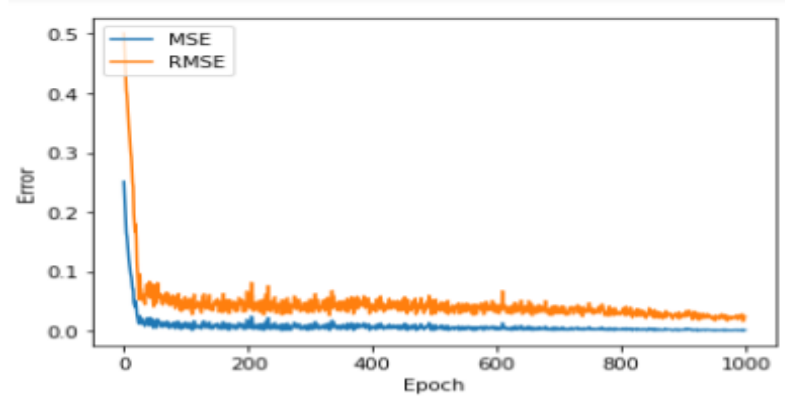

Figure 6. Feedforward Neural NetworkComparing errors with no of epoch 


\subsection{Prediction of $\mathrm{CH}_{4}$ emission from Open farm}

For open farm environment pressure with weight values $0.0159 \pm 0.0010$, humidity with weight values $0.0144 \pm 0.0008$, temperature with weight values $0.0048 \pm 0.0007$ and wind speed weight values $0.0004 \pm 0.0002$ are most important features for prediction of $\mathrm{CH}_{4}$ emission. Fig. 7 shows the weight values along with features.

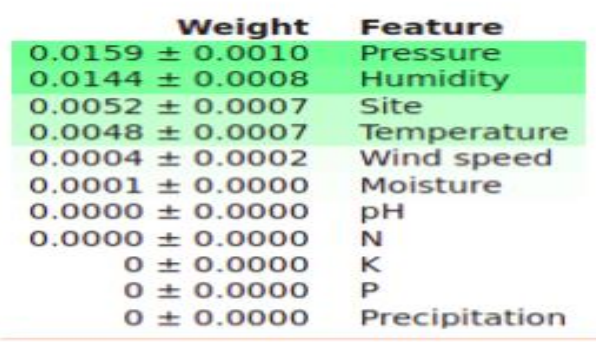

Figure 7. Weight feature of soil and climatic attribute

The experimental result shows that model with 4 layer gives good accuracy in terms of RMSE values i.e. 0.0171 with 1000 epoch. Table 3 shows the RMSE values with number of layer and epoch values and fig. 8 graph shows comparison of the number of epoch and error values.

Table 3. Number of epoch and layer wise RMSE values

\begin{tabular}{|l|l|c|l|}
\hline Epoch & 3 Layer & 4 Layer & 5 Layer \\
\hline 50 & 0.0555 & 0.0480 & 0.0524 \\
\hline 100 & 0.0429 & 0.0471 & 0.0456 \\
\hline 150 & 0.0425 & 0.0425 & 0.0370 \\
\hline 500 & 0.0314 & 0.0254 & 0.0243 \\
\hline 700 & 0.0249 & 0.0191 & 0.0203 \\
\hline 1000 & 0.0222 & 0.0171 & 0.0183 \\
\hline
\end{tabular}

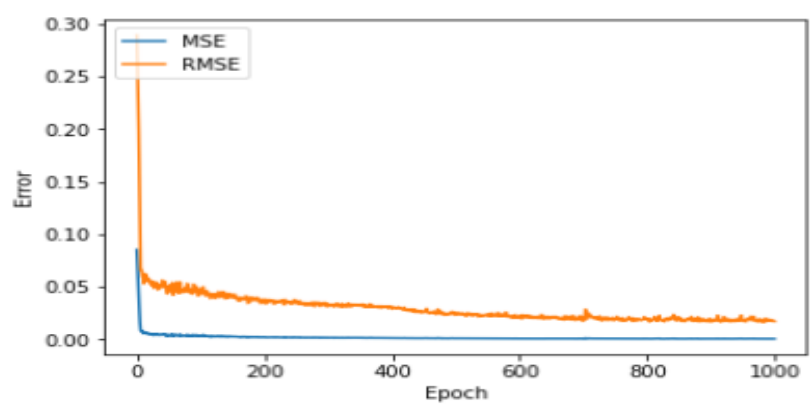

Figure 8. Feedforward Neural NetworkComparing errors with no of epoch

\subsection{Prediction of $\mathrm{CH}_{4}$ emission from Poly house}

For poly house environment humidity with weight values $0.0141 \pm 0.0020$, pressure with weight values $0.0018 \pm 0.0001$, temperature with weight values $0.0008 \pm 0.0002$ and wind speed weight values $0.0006 \pm 0.0003$ are most important features for prediction of $\mathrm{CH}_{4}$ emission. Fig.9 shows the weight values along with features.

$\begin{array}{rl}\text { Weight } & \text { Feature } \\ 0.0141 \pm 0.0020 & \text { Humidity } \\ 0.0018 \pm 0.0001 & \text { Pressure } \\ 0.0008 \pm 0.0002 & \text { Temperature } \\ 0.0006 \pm 0.0003 & \text { Wind speed } \\ 0.0000 \pm 0.0000 & \mathrm{pH} \\ 0.0000 \pm 0.0000 & \text { Moisture } \\ 0.0000 \pm 0.0000 & \text { Site } \\ 0.0000 \pm 0.0000 & \mathrm{~N} \\ 0 \pm 0.0000 & \mathrm{~K} \\ 0 \pm 0.0000 & \mathrm{P} \\ 0 \pm 0.0000 & \text { Precipitation }\end{array}$

Figure 9. Weight feature of soil and climatic attribute

The experimental result shows that model with 4 layer gives good accuracy in terms of RMSE values i.e. 0.0312 with 1000 epoch. Table 4 shows the RMSE values with number of layer and epoch values and fig. 10 graph shows comparison of the number of epoch and error values.

Table 4. Number of epoch and layer wise RMSE values

\begin{tabular}{|l|l|c|l|}
\hline Epoch & 3 Layer & 4 Layer & 5 Layer \\
\hline 50 & 0.2706 & 0.0761 & 0.0599 \\
\hline 100 & 0.2223 & 0.0643 & 0.0559 \\
\hline 150 & 0.1768 & 0.0610 & 0.0566 \\
\hline 500 & 0.0494 & 0.0413 & 0.0496 \\
\hline 700 & 0.0448 & 0.0400 & 0.0438 \\
\hline 1000 & 0.0424 & 0.0312 & 0.0342 \\
\hline
\end{tabular}

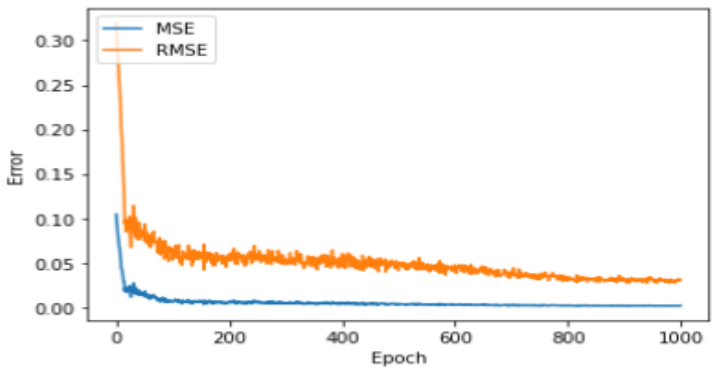

Figure 10. Feedforward Neural NetworkComparing errors with no of epoch

\subsection{Prediction of total GHG emission from Open farm}


Pressure with weight values $0.040 \pm 0.0001$ is a major affecting factor for total greenhouse gases in open farm environment. Pressure plays major role while Humidity with weight values $0.0003 \pm$ 0.0000 plays as minor role for total GHG emission from open farm. Fig. 11 shows the weight values with feature importance.

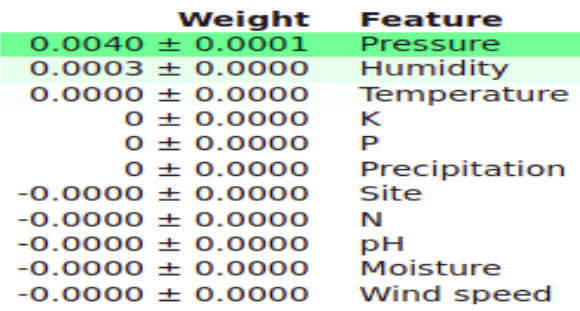

Figure 11. Weight feature of soil and climatic attribute

The experimental result shows that model with 4 layer gives good accuracy in terms of RMSE values i.e. 0.0054 with 1000 epoch. Table 5 shows the RMSE values with number of layer and epoch values and fig.12 graph shows comparison of the number of epoch and error values.

Table 5. Number of epoch and layer wise RMSE values

\begin{tabular}{|l|l|c|l|}
\hline Epoch & 3 Layer & 4 Layer & 5 Layer \\
\hline 50 & 0.0166 & 0.0120 & 0.0194 \\
\hline 100 & 0.0114 & 0.0121 & 0.0154 \\
\hline 150 & 0.0113 & 0.0109 & 0.0134 \\
\hline 500 & 0.0101 & 0.0103 & 0.0125 \\
\hline 700 & 0.0083 & 0.0078 & 0.0109 \\
\hline 1000 & 0.0020 & 0.0054 & 0.0031 \\
\hline
\end{tabular}

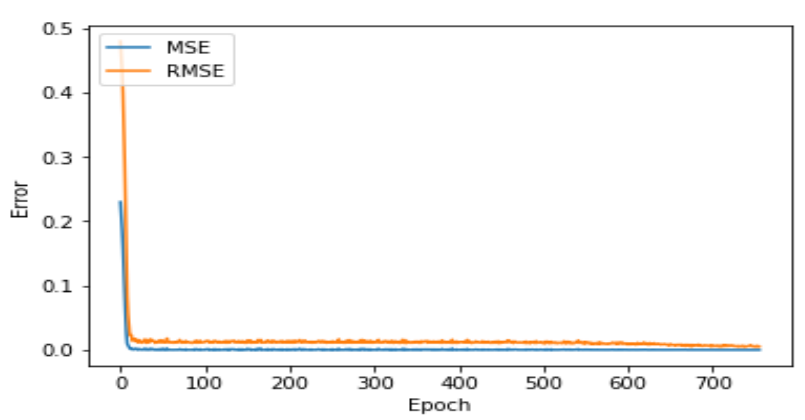

Figure 12. Feedforward Neural NetworkComparing errors with no of epoch

\subsection{Prediction of total GHG emission from Poly house}

Pressure with weight value $0.0009 \pm 0.0001$ is a major factor for emission of greenhouse gases for poly house environment while humidity with weight values $0.0001 \pm 0.0000$ as a minor factor. In general, throughout the analysis, Pressure and Humidity can be seen as constant factors for emission of GHG while other factors cannot be neglected but are important in specific manner. Fig.13 shows the weight values with features importance.

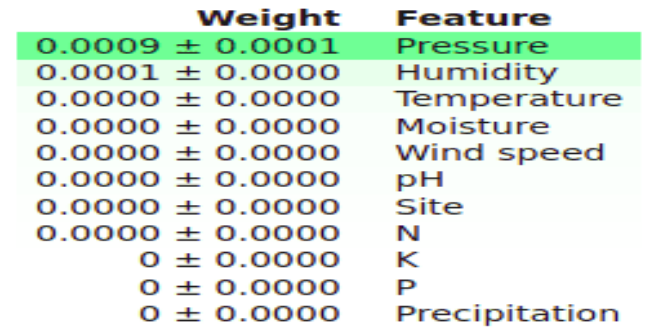

Figure 13. Weight feature of soil and climatic attribute

The experimental result shows that model with 4 layer gives good accuracy in terms of RMSE values i.e. 0.0106 with 1000 epoch. Table 6 shows the RMSE values with number of layer and epoch values and fig. 14 graph shows comparison of the number of epoch and error values.

Table 6. Number of epoch and layer wise RMSE values

\begin{tabular}{|l|l|c|l|}
\hline Epoch & 3 Layer & 4 Layer & 5 Layer \\
\hline 50 & 0.2203 & 0.0116 & 0.0613 \\
\hline 100 & 0.0500 & 0.0139 & 0.0334 \\
\hline 150 & 0.0231 & 0.0136 & 0.0175 \\
\hline 500 & 0.0338 & 0.0140 & 0.0132 \\
\hline 700 & 0.0199 & 0.0137 & 0.0247 \\
\hline 1000 & 0.0198 & 0.0106 & 0.0228 \\
\hline
\end{tabular}

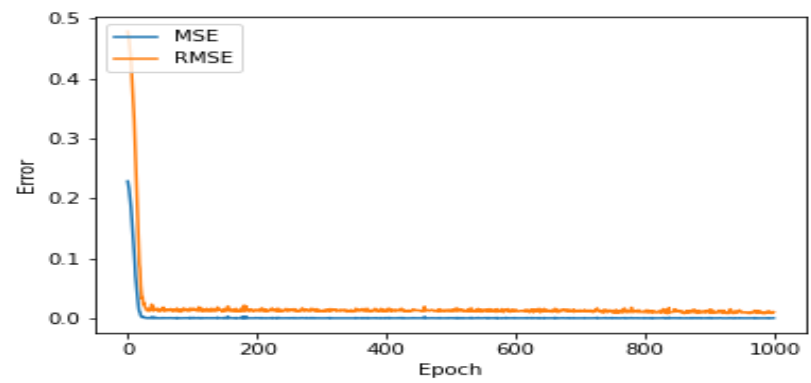

Figure 14. Feedforward Neural NetworkComparing errors with no of epoch 


\section{Conclusion}

As the concentration of GHG rises it raises the temperature on the globe causing the Global Warming. Modification in agriculture management practices may reduce the GHG emission. We have built the Deep Learning Model for predicting $\mathrm{CO}_{2}$ and $\mathrm{CH}_{4}$ emission for Onion crop from open farm and poly house. The GHG emission may vary in open farm and poly house for onion crop because the environment is controlled in poly house as compared to open farm. For this study we collected the field data of soil attributes, climatic attributes and $\mathrm{CO}_{2}, \mathrm{CH}_{4}$ greenhouse gases from the experiment field. We hyper tune the model with 3 , 4 and 5 layers with different epoch. For Open farm and Ploy house the RMSE values for $\mathrm{CO}_{2}$ are 0.0112 and 0.0238 and for $\mathrm{CH}_{4} 0.0171$ and 0.0312 with 4 layer model with 1000 epoch. Deep Learning Model also predicted that Nitrogen, Moisture, Pressure, Humidity and Temperature are major affecting factors for greenhouse gases in open field and poly house environment for onion crop.

The study conclude that model indicate good prediction response for $\mathrm{CO}_{2}$ and $\mathrm{CH}_{4}$ emission along with major influencing attribute for Onion crop from Open farm and Poly house. Hence our study will help the farmers for better understanding of agriculture management practices.

\section{References}

[1] Alicja Kolasa-Więcek, "Use of Artificial Neural Networks in Predicting Direct Nitrous Oxide Emissions from Agricultural Soils," Ecological Chemistry and Engineering S, pp. 419-428, Volume 20: Issue 2 , DOI: https://doi.org/10.2478/eces-2013-0030,(2013)

[2] Ashkan Nabavi-Pelesaraei, Reza Abdi, Shahin Rafiee "Neural network modeling of energy use and greenhouse gas emissions of watermelon production systems," Journal of the Saudi Society of Agriculture Sciences, http://dx.doi.org/10.1016/j.jssas.2014.05.001, (2014)

[3] Andreas Kamilaris and Francesc X. PrenafetaBoldú, "Deep Learning in Agriculture: A Survey," Computers and Electronics in
Agriculture, Elsevier. DOI:

10.1016/j.compag.2018.02.016, (2018)

[4] Aung Zaw Oo, Khin Thuzar Win and Sonoko Dorothea Bellingrath-Kimura, "Within field spatial variation in methane emissions from lowland rice in Myanmar," Springer Plus, pp. 1-11, DOI 10.1186/s40064-015-0901-2, (2015)

[5] B. J. Zebarth, P. Rochette, D. L. Burton and M. Price,"Effect of fertilizer nitrogen management on $\mathrm{N} 2 \mathrm{O}$ emissions in commercial corn fields," Canadian journal of soil science, pp. 189-195,(2008)

[6] B. Khoshnevisan, S. Rafiee, M. Omid, H. Mousazadeh, "Developing an Artificial Neural Networks Model for Predicting Output Energy and GHG Emission of Strawberry Production," International Journal of Applied Operational Research ,Vol. 3, No. 4, pp. 4354, (2013)

[7] Cai - Ma, "Carbon emission prediction model of agroforestry ecosystem based on support vector regression machine," Applied Ecology and Environmental Research pp. 6397-6413, DOI:

http://dx.doi.org/10.15666/aeer/1703 6397641 $\underline{3,(2019)}$

[8] Chusnul Arif, Budi Indra Setiawan, Nur Aini Iswati Hasanah, Masaru Mizoguchi, "Estimating Greenhouse Gas Emissions from Irrigated Paddy Fields in Indonesia under Various Water Managements," IOP Conf. Series: Materials Science and Engineering, pp. 1-8, doi:10.1088/1757-899X/557/1/012034, (2019)

[9] Dinesh Panday, Nsalambi V. Nkongolo, "Effect of Soil Air and Water on Greenhouse Gases Emissions in a Corn-Soybean Rotation," Department of Agriculture and Environ-mental Sciences, Lincoln University, Jefferson City, MO 65101-0029, USA, (2015)

[10] Forkuor G, Hounkpatin OKL, Welp G, Thiel M , "High Resolution Mapping of Soil Properties Using Remote Sensing Variables in South-Western Burkina Faso: A Comparison of Machine Learning and Multiple Linear Regression Models," pp. 1-21, PLoS ONE, doi:10.1371/journal.pone.0170478, (2017) 
[11] Guifang Liu, Weijun Xu, Yongwu Dai, Zhongyue $\mathrm{Xu}$, "Analysis and Prediction of Greenhouse Gas Emissions from Wheat Production in China," Chemical Engineering Transactions, pp. 1315-1320, DOI:10.3303/CET1870220, (2018)

[12] Homa Hosseinzadeh-Bandbafha, Ashkan Nabavi-Pelesaraei, and Shahaboddin Shamshir-band ," Investigations of Energy Consumption and Greenhouse Gas Emissions of Fattening Farms Using Artificial Intelligence Methods," Environmental Progress \& Sustainable Energy, DOI 10.1002/ep, American Institute of Chemical Engineers, (2017)

[13] Hyeon Ji Song, Jin Ho Lee, Hyun-Cheol Jeong, Eun-Jung Choi, Taek-Keun Oh, Chang-Oh Hong and Pil Joo Kim, "Effect of straw incorporation on methane emission in rice paddy: conversion factor and smart straw management,". Appl Biol Chem pp. 1-13, Springer, https://doi.org/10.1186/s13765-0190476-7, (2019)

[14] Johnson Masaka,Justice Nyamangara, Menas Wuta, "Nitrous oxide emissions from wetland soil amended with two types of cattle manure," Interantional Jouranl of Recycl Org Waste Agriculture, pp.1-16, Springer, DOI 10.1007/s40093-016-0123-9, (2016)

[15] Kingsley Appiah,Jianguo Du, Rhoda Appah and Daniel Quacoe, "Prediction of Potential Carbon Dioxide Emissions of Selected Emerging Economies Using Artificial Neural Network," Journal of Environmental Science and Engineering, pp. 321-335, doi:10.17265/2162-5298/2018.08.003, (2018)

[16] Leopord Uwamahoro, Dr. Papias Niyigena, "Deep Learning in Greenhouse Gases Emissions from Agriculture Activities in Rwanda using Long Short Term Memory Recurrent Neural Network," International Research Journal of Engineering and Technology (IRJET), Volume: 06 Issue: 10 , e-ISSN: 2395-0056, p-ISSN: 2395-0072, (2019)

[17] Mphethe Tongwanea, Thandile Mdlambuzi, Mokhele Moeletsia, Mitsuru Tsuboa, Vuyo Mliswa, Lunga Grootboom, “Greenhouse gas emissions from different crop production and management practices in South Africa," Environmental Development, Elsevier, (2016)

[18] Safwan Mohammed, Karam Alsafadi, István Takács \& Endre Harsányi ,'Contemporary changes of greenhouse gases emission from the agricultural sector in the EU-27," Geology, Ecology, and Landscapes, DOI: 10.1080/24749508.2019.1694129, (2019)

[19] Safieh Javadinejad, Saied Eslamian, Kaveh Ostad-Ali-Askari, "Investigation of monthly and seasonal changes of methane gas with respect to climate change using satellite data," Applied Water Science pp.1-8 , Springer, https://doi.org/10.1007/s13201-019-1067-9, (2019)

[20] Witsanu Attavanich, "The Effect of Climate Change on Thailand's Agriculture," online at https://mpra.ub.uni-muenchen.de/84005/

MPRA Paper No. 84005, posted 22 January 2018 06:32 UTC, (2018)

[21] "Greenhouse gas concentrations in atmosphere reach yet another high", https://public.wmo.int/en/media/pressrelease/greenhouse-gas-concentrationsatmosphere-reach-yet-another-high Accessed on 10-06-2020 at 4.26 P.M. (fig-1)

[22] "Assessing the Fit of Regression Models", https://www.theanalysisfactor.com/assessingthe-fit-of-regression models/ Accessed on 1106-2020 at 5.05 P.M.

[23] Kerstin Jantke, Martina J. Hartmann, Livia Rasche , Benjamin Blanz and Uwe A. Schneider, "Agricultural Greenhouse Gas Emissions: Knowledge and Positions of German Farmers," Land 2020, 9, 130; doi:10.3390/land9050130, www.mdpi.com/journal/land (2020)

[24] H. Flessa, R. Ruser , P. Dörsch , T. Kamp, M.A. Jimenez J.C. Munch, F. Beese, "Integrated evaluation of greenhouse gas emissions (CO2, $\mathrm{CH} 4, \mathrm{~N} 2 \mathrm{O})$ from two farming systems in southern Germany",Agriculture, Ecosystems and Environment Volume 91, Issues 1-3 pp. 175189, $\quad$ https://doi.org/10.1016/S0167$\underline{8809(01) 00234-1},(2002)$

[25] Sylvia H. Vettera, Tek B. Sapkota, Jon Hillier, Clare M. Stirling, Jennie I. Macdiarmid, 
Lukasz Aleksandrowicz, Rosemary Green, Edward J.M. Joy, Alan D. Dangour,Pete Smith," Greenhouse gas emissions from agricultural food production to supply Indian diets: Implications for climate change mitigation," Agriculture, Ecosystems and Environment pp. 234-241

[26] Grant, B., Smith, W.N., Desjardins, R. et al. Estimated $\mathrm{N} 2 \mathrm{O}$ and $\mathrm{CO} 2$ Emissions as Influenced by Agricultural Practices in Canada. Climatic Change 65, pp. 315-332 https://doi.org/10.1023/B:CLIM.0000038226. 60317.35, (2004)

[27] Abderrachid Hamrani, Abdolhamid Akbarzadeh,Chandra A.Madramootoo, "Machine learning for predicting greenhouse gas emissions from agricultural soils", Science of The Total Environment Volume 741, 1 140338,

https://doi.org/10.1016/j.scitotenv.2020.14033 $\underline{8},(2020)$ 